\title{
Article \\ Clinical Outcomes in Patients with Ischemic versus Non-Ischemic Cardiomyopathy after Angiotensin-Neprilysin Inhibition Therapy
}

\author{
Mohammad Abumayyaleh ${ }^{1,2}\left(\mathbb{0}\right.$, , Christina Pilsinger ${ }^{1}$, Ibrahim El-Battrawy ${ }^{1,2, *}$, Marvin Kummer ${ }^{1,2}$, \\ Jürgen Kuschyk ${ }^{1}$, Martin Borggrefe ${ }^{1,2}$, Andreas Mügge ${ }^{3}$, Assem Aweimer ${ }^{3,+}$ and Ibrahim Akin ${ }^{1,2,+}$ \\ 1 First Department of Medicine, University Medical Center Mannheim, University Heidelberg, \\ 68167 Mannheim, Germany; mohammad.abumayyaleh@medma.uni-heidelberg.de (M.A.); \\ christina.pilsinger@gmail.com (C.P.); marvin.kummer@yahoo.de (M.K.); \\ Juergen.kuschyk@medma.uni-heidelberg.de (J.K.); Martin.borggrefe2006@gmail.com (M.B.); \\ Ibrahim.Akin@umm.de (I.A.) \\ 2 DZHK (German Centre for Cardiovascular Research) Partner Site, Heidelberg-Mannheim, \\ 68167 Mannheim, Germany \\ 3 Department of Cardiology and Angiology, Bergmannsheil University Hospitals, Ruhr University of Bochum, \\ 44789 Bochum, Germany; andreas.muegge@bergmannsheil.de (A.M.); \\ assem.aweimer@bergmannsheil.de (A.A.) \\ * Correspondence: ibrahim.elbattrawy2006@gmail.com; Tel.: +49-621-383-1447; Fax: +49-621-383-1474 \\ + These authors contributed equally to this work.
}

\section{check for} updates

Citation: Abumayyaleh, M.; Pilsinger, C.; El-Battrawy, I.; Kummer, M.; Kuschyk, J.; Borggrefe, M.; Mügge, A.; Aweimer, A.; Akin, I. Clinical Outcomes in Patients with Ischemic versus Non-Ischemic Cardiomyopathy after AngiotensinNeprilysin Inhibition Therapy. J. Clin Med. 2021, 10, 4989. https://doi.org/ $10.3390 /$ jcm10214989

Academic Editor: Francesco Pelliccia

Received: 22 September 2021

Accepted: 25 October 2021

Published: 27 October 2021

Publisher's Note: MDPI stays neutral with regard to jurisdictional claims in published maps and institutional affiliations.

Copyright: (c) 2021 by the authors Licensee MDPI, Basel, Switzerland. This article is an open access article distributed under the terms and conditions of the Creative Commons Attribution (CC BY) license (https:/ / creativecommons.org/licenses/by/ $4.0 /)$.
Abstract: Background: The angiotensin receptor-neprilysin inhibitor (ARNI) decreases cardiovascular mortality in patients with chronic heart failure with a reduced ejection fraction (HFrEF). Data regarding the impact of ARNI on the outcome in HFrEF patients according to heart failure etiology are limited. Methods and results: One hundred twenty-one consecutive patients with HFrEF from the years 2016 to 2017 were included at the Medical Centre Mannheim Heidelberg University and treated with ARNI according to the current guidelines. Left ventricular ejection fraction (LVEF) was numerically improved during the treatment with ARNI in both patient groups, that with ischemic cardiomyopathy ( $n=61$ ) (ICMP), and that with non-ischemic cardiomyopathy ( $n=60)$ (NICMP); $p=0.25$. Consistent with this data, the NT-proBNP decreased in both groups, more commonly in the NICMP patient group. In addition, the glomerular filtration rate (GFR) and creatinine changed before and after the treatment with ARNI in both groups. In a one-year follow-up, the rate of ventricular tachyarrhythmias (ventricular tachycardia and ventricular fibrillation) tended to be higher in the ICMP group compared with the NICMP group (ICMP 38.71\% vs. NICMP 17.24\%; $p=0.07$ ). The rate of one-year all-cause mortality was similar in both groups (ICMP $6.5 \%$ vs. NICMP $6.6 \%$; log-rank $=0.9947)$. Conclusions: This study shows that, although the treatment with ARNI improves the LVEF in ICMP and NICMP patients, the risk of ventricular tachyarrhythmias remains higher in ICMP patients in comparison with NICMP patients. Renal function is improved in the NICMP group after the treatment. Long-term mortality is similar over a one-year follow-up.

Keywords: ARNI; ICMP; NICMP; sacubitril/valsartan; tachyarrhythmias; outcomes

\section{Introduction}

The angiotensin receptor-neprilysin inhibitor (ARNI), which consists of the neprilysin inhibitor sacubitril and the angiotensin receptor blocker (ARB) valsartan, is used to treat symptomatic heart failure with a reduced ejection fraction (HFrEF) [1]. Neprilysin, as an endopeptidase, degrades and disables natriuretic peptides (NP) [2]. Valsartan binds to angiotensin type I receptor (AT1) and blocks angiotensin II. The combined effect of ARNI is associated with better hemodynamics in patients with heart failure (HF) compared with ARB alone [3]. In PARADIGM-HF (Prospective Comparison of ARNI with ACEI to 
Determine Impact on Global Mortality and Morbidity in Heart Failure), treatment with ARNI in patients suffering from HFrEF was associated with a lower rate of cardiovascular deaths as well as hospitalization for HF compared with enalapril [1]. In patients with heart failure with preserved ejection fraction (HFpEF), ARNI did not reduce the total hospitalization rate due to HF and deaths from cardiovascular causes [4]. On the other hand, the improvement in glycemic control in patients suffering from HFrEF and type 2 diabetes was observed [5]. In addition, a patient under ARNI therapy had an improved health status compared with patients without ARNI therapy and with decreased heart failure symptoms, improved physical functions, and better quality of life [6]. In one analysis of PARADIGM-HF, the advantage of ARNI over angiotensin-converting enzyme inhibitor (ACEI) did not depend on a certain etiology [7]. However, ischemic etiology was an independent predictor for discontinuation of the treatment with ARNI [8]. Further data on the role of etiology in the treatment of ARNI are limited.

Regarding the treatment with ACEI or ARB, one study has shown that ACEI or ARB was associated with a lower survival rate in ischemic cardiomyopathy (ICMP) compared with non-ischemic cardiomyopathy (NICMP) [9]. At long-term follow-up, another study presented a higher mortality rate in patients suffering from ICMP than in patients suffering from NICMP who were medicated with ACEI or ARB [10]. Furthermore, atrial fibrillation (AF) patients with ICMP showed a higher rate of cardiovascular death in comparison with AF patients with NICMP, under treatment with ACEI or ARB [11].

Since there was a lack in the data concerning ARNI therapy with respect to different etiologies of HF, we analyzed a consecutive patient cohort with ICMP versus NICMP to explore the impact of ARNI in patients with different HF etiologies. The present study aims to compare the one-year mortality in HFrEF patients with ICMP compared with HFrEF patients with NICMP after the ARNI treatment.

\section{Methods}

One hundred twenty-seven consecutive patients diagnosed with HFrEF between 2016 and 2017 at the University Medical Centre Mannheim Heidelberg University were initially screened. Six patients were excluded because of uncertain information regarding the etiology of HF. However, the data of one hundred twenty-one patients were complete (Figure 1). Chronic HFrEF was diagnosed in accordance with the HF guidelines of the European Society of Cardiology [12]. Patients were included if they (1) had HF symptoms with New York Heart Association (NYHA) functional class II to IV despite optimal HF medication, (2) hd a left ventricular ejection fraction (LVEF) $\leq 40 \%$, and (3) tolerated ARNI therapy (initially at a dose of $24 / 26 \mathrm{mg}$ twice daily, which was increased to $97 / 103 \mathrm{mg}$ twice daily).

One hundred twenty-one patients were divided with respect to HF etiology into two groups: ICMP $(n=61)$ and NICMP $(n=60)$. The data about medication intake and side effects as well as clinical outcomes were collected by chart review and/or telephone review. Treatment was discontinued in patients who suffered side effects (cough, symptomatic hypotension, hyperkaliemia, increased creatinine, and depression of kidney function). Clinical parameters (systolic and diastolic blood pressure as well as heart rate), laboratory values (glomerular filtration rate (GFR), creatinine, potassium, and N-terminal prohormone of brain natriuretic peptide (NT-proBNP)), electrocardiogram (ECG) data, and medical history were collected before and after the treatment with ARNI at six- and twelve-month followups. Furthermore, echocardiography was conducted before ARNI treatment and during clinical visits at six- and twelve-month follow-ups after the beginning of the treatment. The presentation of ventricular tachyarrhythmias was assessed by interrogating implantable cardioverter-defibrillators (ICD) or cardiac resynchronization therapy devices (CRT).

Worsening renal function (WRF) was defined as a change in serum creatinine, specifically as an increase in serum creatinine $>0.3 \mathrm{mg} / \mathrm{dL}$ compared with baseline creatinine value or an increase of serum creatinine within seven days $[13,14]$. Estimated GFR was calculated by the abbreviated MDRD equation. 
This study was conducted in accordance with the Declaration of Helsinki. The study protocol was recently approved by the Ethics Committee of the University Medical Centre Mannheim.

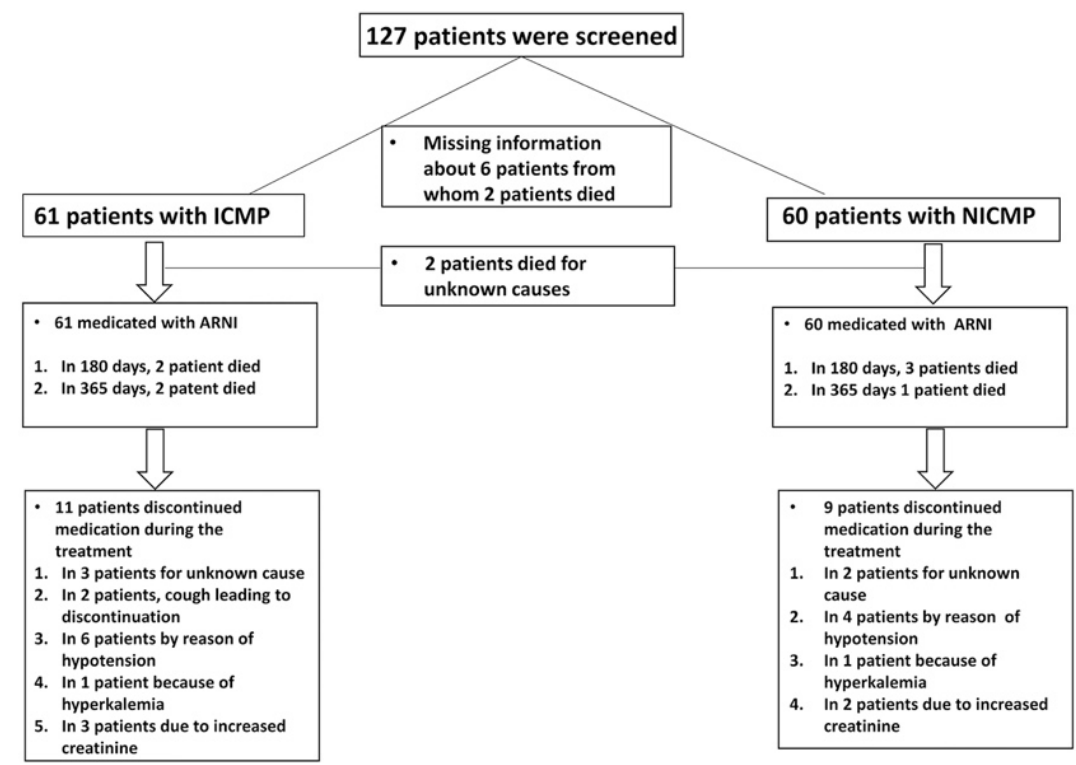

Figure 1. Study design.

\subsection{Outcome}

We described one-year all-cause mortality as the primary endpoint. Ventricular tachyarrhythmias, change in kidney function, and the improvement of LVEF as secondary endpoints were also evaluated.

\subsection{Statistical Analysis}

Continuous variables with a normal distribution are presented as mean \pm standard deviation, and those with a non-normal distribution are presented as median (min-max). Categorical variables are presented as frequencies and percentages (\%). The Shapiro-Wilk test was used to test normal distribution. Student's $t$-test and Mann-Whitney U test were used to compare normal or nonnormal distributions of continuous variables, respectively. The Chi-squared test or Fischer's exact test was used for distribution analysis to compare categorical variables. Wilcoxon's signed-rank test was used for paired nonparametric quantitative variables, while the McNemar test was used for paired qualitative variables. We estimated the survival rate using the Kaplan-Meier estimation. Predictors of mortality were identified by univariate analysis. Predictors with $p<0.05$ were analyzed by the Cox multivariate regression. Statistical analysis was performed with SPSS, Version 23.0 (IBM SPSS Statistics for Windows. Armonk, NY, USA). $p<0.05$ was recognized as statistically significant.

\section{Results}

\subsection{Baseline Characteristics before and after Sacubitril-Valsartan}

The patient characteristics before and after ARNI are listed in Table 1. One hundred twenty-seven consecutive patients were screened between the years 2016 and 2017. Six patients were excluded because of a lack of information about HF etiology. One hundred twenty-one patients were divided with respect to HF etiology into two groups: ICMP $(n=61)$ and NICMP $(n=60)$. Forty-four patients $(73.3 \%)$ were documented to have an idiopathic dilated cardiomyopathy, five patients $(8.3 \%)$ had hypertrophic cardiomyopathy, four patients $(6.7 \%)$ had a mixed phenotype (dilated and hypertrophic), one patient $(1.7 \%)$ had non-compaction cardiomyopathy, one patient $(1.7 \%)$ had chemotherapyrelated cardiomyopathy, and five patients $(8.3 \%)$ had other types of cardiomyopathy. 
The risk factors for cardiovascular disease in both groups were comparable (smoking: $24.07 \%$ in ICMP vs. $25.45 \%$ in NICMP, $p=0.87$; diabetes mellitus type II: $39.34 \%$ in ICMP vs. $27.59 \%$ in NICMP, $p=0.18$; and hypertension: $76.67 \%$ in ICMP vs. $62.96 \%$ in NICMP, $p=0.11$ ). GFR and creatinine changed before and after the treatment with ARNI in both groups: GFR from $52.91 \pm 26.02 \mathrm{~mL} / \mathrm{min}$ to $42.10 \pm 19.05 \mathrm{~mL} / \mathrm{min}$ and creatinine from $1.60 \pm 0.52 \mathrm{mg} / \mathrm{dL}$ to $1.99 \pm 1.24 \mathrm{mg} / \mathrm{dL}$ in ICMP patients, $p=002$ and $p=0.01$, and GFR from $60.63 \pm 21.43 \mathrm{~mL} / \mathrm{min}$ to $70.52 \pm 28.08 \mathrm{~mL} / \mathrm{min}$ and creatinine from $1.19 \pm 0.53 \mathrm{mg} / \mathrm{dL}$ to $1.19 \pm 0.47 \mathrm{mg} / \mathrm{dL}$ in NICMP patients, $p=0.001$ and $p=0.26$. In contrast, NT-proBNP decreased significantly after the treatment with ARNI in both groups (in the ICMP group, from $6266.68 \mathrm{ng} / \mathrm{L}$ to $6191.76 \mathrm{ng} / \mathrm{L}, p=0.24$, and in the NICMP group, from $5132.82 \mathrm{ng} / \mathrm{L}$ to $1170.69 \mathrm{ng} / \mathrm{L}, p=0.01$. In addition, systolic and diastolic blood pressure (BP) decreased in both groups (in systolic BP in the ICMP group, from $132.14 \pm 30.28 \mathrm{mmHg}$ to $118.62 \pm 27.17 \mathrm{mmHg}$, $p=0.28$, and in the NICMP group, from $128.73 \pm 14.50$ to $113.81 \pm 17.67 \mathrm{mmHg}, p=0.23)$. Furthermore, EF was numerically improved at follow-up in both groups (Table 1).

Table 1. Baseline characteristics of NICMP and ICMP patients presenting at the beginning of the treatment with ARNI and one-year follow-up.

\begin{tabular}{|c|c|c|c|c|c|c|}
\hline Variables & $\begin{array}{c}\text { NICMP Patients } \\
\text { before ARNI } \\
n=60\end{array}$ & $\begin{array}{c}\text { ICMP Patients } \\
\text { before ARNI } \\
n=61\end{array}$ & $p$-Value ${ }^{1}$ & $\begin{array}{l}\text { NICMP Patients } \\
\text { after ARNI } \\
n=60\end{array}$ & $\begin{array}{c}\text { ICMP Patients after } \\
\text { ARNI } \\
n=61\end{array}$ & $p$-Value ${ }^{2}$ \\
\hline $\begin{array}{c}\text { Demographics } \\
\text { Age, mean } \pm \text { SD } \\
\text { Gender (male) } n(\%)\end{array}$ & $\begin{array}{c}61.8 \pm 11 \\
43 / 59(72.9)\end{array}$ & $\begin{array}{c}69.7 \pm 11 \\
54 / 61(88.5)\end{array}$ & $\begin{array}{c}<0.001 \\
0.03\end{array}$ & - & - & - \\
\hline $\begin{array}{c}\text { Clinic parameter } \\
\text { Systolic } \mathrm{BP} \mathrm{mmHg}, \\
\text { mean } \pm \mathrm{SD} \\
\text { Diastolic } \mathrm{BP} \mathrm{mmH} \text {, mean } \pm \mathrm{SD} \\
\text { Heart rate } \mathrm{Bpm} \text {, mean } \pm \mathrm{SD}\end{array}$ & $\begin{array}{c}128.73 \pm 14.50 \\
82.09 \pm 9.27 \\
76.30 \pm 15.02 \\
\end{array}$ & $\begin{array}{c}132.14 \pm 30.28 \\
76.43 \pm 12.41 \\
78.95 \pm 16.61 \\
\end{array}$ & $\begin{array}{l}0.28 \\
0.27 \\
0.48\end{array}$ & $\begin{array}{c}113.81 \pm 17.67 \\
72.00 \pm 12.10 \\
71.34 \pm 13.49 \\
\end{array}$ & $\begin{array}{c}118.62 \pm 27.17 \\
69.52 \pm 20.00 \\
73.62 \pm 18.86 \\
\end{array}$ & $\begin{array}{l}0.23 \\
0.87 \\
0.72\end{array}$ \\
\hline $\begin{array}{c}\text { Laboratory values } \\
\text { GFR }(\mathrm{ml} / \mathrm{min}), \text { mean } \pm \mathrm{SD} \\
\text { Creatinine }(\mathrm{mg} / \mathrm{dL}), \text { mean } \pm \mathrm{SD} \\
\text { Potassium }(\mathrm{mmol} / \mathrm{L}), \text { median } \\
(\mathrm{min} .-\mathrm{max}) \\
\operatorname{proBNP}(\mathrm{ng} / \mathrm{L}), \text { mean } \pm \mathrm{SD}\end{array}$ & $\begin{array}{c}60.63 \pm 21.43 \\
1.19 \pm 0.53 \\
4.03(2.1-5.10) \\
5132.82 \pm 6394.67\end{array}$ & $\begin{array}{c}52.91 \pm 26.02 \\
1.60 \pm 0.52 \\
4.10(3.29-5.70) \\
6266.68 \pm 5794.73\end{array}$ & $\begin{array}{c}0.002 \\
0.01 \\
0.62 \\
0.24\end{array}$ & $\begin{array}{c}70.52 \pm 28.08 \\
1.19 \pm 0.47 \\
4.30(3.10-6.60) \\
1170.69 \pm 1631.81\end{array}$ & $\begin{array}{c}42.10 \pm 19.05 \\
1.99 \pm 1.24 \\
4.20(3.40-6.20) \\
6190 \pm 7623.41\end{array}$ & $\begin{array}{c}0.001 \\
0.02 \\
0.26 \\
0.01\end{array}$ \\
\hline $\begin{array}{c}\text { ECG Data mean } \pm \text { SD } \\
\text { PQ-Time } \\
\text { QT-Time } \\
\text { QTc-time }\end{array}$ & $\begin{array}{l}170.80 \pm 37.74 \\
427.11 \pm 57.67 \\
470.14 \pm 55.04\end{array}$ & $\begin{array}{l}182.53 \pm 29.91 \\
437.24 \pm 66.05 \\
478.83 \pm 44.39\end{array}$ & $\begin{array}{l}0.29 \\
0.59 \\
0.45\end{array}$ & $\begin{array}{l}164.46 \pm 21.73 \\
422.85 \pm 47.46 \\
455.92 \pm 33.66\end{array}$ & $\begin{array}{l}188.60 \pm 43.72 \\
430.70 \pm 40.31 \\
471.00 \pm 39.30\end{array}$ & $\begin{array}{l}0.08 \\
0.25 \\
0.35\end{array}$ \\
\hline $\begin{array}{c}\text { Medical history } \boldsymbol{n}(\mathbf{\%}) \\
\text { Smoking } \\
\text { Diabetes mellitus type II } \\
\text { Hypertension } \\
\text { COPD } \\
\text { Asthma } \\
\text { History of malignancy } \\
\text { Stroke } \\
\text { Bleeding } \\
\text { Atrial fibrillation }\end{array}$ & $\begin{array}{l}14 / 55(25.45) \\
16 / 58(27.59) \\
34 / 54(62.96) \\
10 / 59(16.95) \\
1 / 59(1.64) \\
5 / 59(8.47) \\
6 / 58(10.34) \\
2 / 59(3.39) \\
11 / 35(31.4)\end{array}$ & $\begin{array}{l}13 / 54(24.07) \\
24 / 61(39.34) \\
46 / 60(76.67) \\
7 / 61(11.48) \\
0 / 61(0.00) \\
6 / 60(10.00) \\
5 / 60(8.33) \\
3 / 61(4.92) \\
19 / 41(46.3)\end{array}$ & $\begin{array}{l}0.87 \\
0.18 \\
0.11 \\
0.39 \\
0.49 \\
1.00 \\
0.76 \\
1.00 \\
0.19\end{array}$ & $\begin{array}{l}11 / 52(21.15) \\
18 / 59(30.51) \\
36 / 55(65.45) \\
13 / 60(21.67) \\
1 / 58(0.00) \\
4 / 57(7.02) \\
6 / 57(10.53) \\
1 / 58(1.72) \\
18 / 35(51.4)\end{array}$ & $\begin{array}{c}8 / 44(18.18) \\
24 / 58(41.38) \\
40 / 52(76.92) \\
8 / 53(15.09) \\
0 / 49(0.00) \\
5 / 53(9.43) \\
5 / 56(8.93) \\
2 / 57(3.51) \\
25 / 40(62.5)\end{array}$ & $\begin{array}{l}0.72 \\
0.22 \\
0.19 \\
0.37 \\
0.49 \\
0.74 \\
1.00 \\
0.62 \\
0.33\end{array}$ \\
\hline $\begin{array}{c}\text { NYHA-Classification } \\
\text { I } \\
\text { II } \\
\text { III } \\
\text { IV } \\
\text { EF }(\%) \text { mean } \pm \text { SD }\end{array}$ & $\begin{array}{l}1 / 45(2.22) \\
16 / 45(35.56) \\
26 / 45(57.78) \\
2 / 45(4.44) \\
25.31 \pm 7.68\end{array}$ & $\begin{array}{c}0 / 45(0.00) \\
6 / 45(13.33) \\
34 / 45(75.56) \\
5 / 45(11.11) \\
24.13 \pm 8.39\end{array}$ & $\begin{array}{l}0.05 \\
0.05 \\
0.05 \\
0.05 \\
0.58\end{array}$ & $\begin{array}{l}3 / 32(9.38) \\
14 / 32(43.75) \\
14 / 32(43.75) \\
1 / 32(3.13) \\
29.63 \pm 10.01\end{array}$ & $\begin{array}{c}4 / 41(9.76) \\
9 / 41(21.95) \\
22 / 41(53.66) \\
6 / 41(14.63) \\
32.13 \pm 7.53\end{array}$ & $\begin{array}{l}0.14 \\
0.14 \\
0.14 \\
0.14 \\
0.25\end{array}$ \\
\hline $\begin{array}{c}\text { Electronic cardiac device } n \mathbf{( \% )} \\
\text { CRT } \\
\text { ICD } \\
\text { DDD } \\
\text { CCM } \\
\text { Vagus stimulation }\end{array}$ & $\begin{array}{l}19 / 59(32.20) \\
28 / 60(46.67) \\
1 / 60(1.67) \\
11 / 60(18.33) \\
1 / 60(1.67)\end{array}$ & $\begin{array}{l}15 / 61(24.59) \\
42 / 61(68.85) \\
3 / 61(4.91) \\
17 / 60(28.33) \\
0 / 59(0.00)\end{array}$ & $\begin{array}{l}0.36 \\
0.01 \\
0.62 \\
0.20 \\
1.00\end{array}$ & $\begin{array}{l}25 / 60(41.67) \\
32 / 59(54.24) \\
1 / 60(1.67) \\
13 / 60(21.67) \\
1 / 58(1.72)\end{array}$ & $\begin{array}{c}18 / 60(30.00) \\
46 / 60(76.67) \\
2 / 60(3.33) \\
22 / 60(36.67) \\
0 / 59(0.00)\end{array}$ & $\begin{array}{l}0.18 \\
0.01 \\
1.00 \\
0.07 \\
0.50\end{array}$ \\
\hline $\begin{array}{c}\text { Drugs on admission } n \mathbf{n} \%) \\
\text { Beta-blocker } \\
\text { AT-II-Antagonist } \\
\text { Aldosterone antagonist } \\
\text { ACE-Inhibitor } \\
\end{array}$ & $\begin{array}{l}56 / 59(94.92) \\
14 / 58(24.14) \\
48 / 59(81.36) \\
36 / 58(62.07)\end{array}$ & $\begin{array}{l}56 / 59(94.92) \\
19 / 60(31.67) \\
40 / 60(66.67) \\
30 / 59(50.85)\end{array}$ & $\begin{array}{l}1.00 \\
0.36 \\
0.07 \\
0.22\end{array}$ & $\begin{array}{c}59 / 59(100.00) \\
- \\
46 / 59(77.97) \\
0 / 57(0.00)\end{array}$ & $\begin{array}{c}57 / 58(98.28) \\
- \\
41 / 59(69.49) \\
0 / 56(0.00)\end{array}$ & $\begin{array}{c}0.50 \\
- \\
0.30 \\
-\end{array}$ \\
\hline $\begin{array}{l}\text { Antiarrhythmic drugs } n(\%) \\
\text { Amiodarone }\end{array}$ & $8 / 58(13.79)$ & $11 / 60(18.33)$ & 0.50 & $12 / 59(20.34)$ & $13 / 60(21.67)$ & 0.86 \\
\hline
\end{tabular}

$p$-value ${ }^{1}$ for the comparison between NICMP and ICMP before ARNI; $p$-value ${ }^{2}$ for the comparison between NICMP and ICMP after ARNI; $\mathrm{SD}$, standard deviation; ARNI, angiotensin receptor-neprilysin inhibitor; ICMP, ischemic cardiomyopathy; NICMP, non-ischemic cardiomyopathy; ECG, electrocardiogram; BP, blood pressure; GFR, glomerular filtration rate; pro-BNP, pro-B-type natriuretic peptide; COPD, chronic obstructive pulmonary disease; EF, ejection fraction; CRT, cardiac resynchronization therapy; ICD, implantable cardioverter-defibrillator; CCM, cardiac contractility modulation; AT-II-Antagonist, angiotensin II receptor antagonist; ACE, angiotensin-converting-enzyme. 


\subsection{Side Effects Leading to Treatment Discontinuation \\ 3.2.1. ICMP Group}

Collectively, eleven ICMP patients (18\%) discontinued the medication during ARNI therapy. Three patients were for an unknown cause. Two patients developed a cough that led them to stop the treatment. In six patients, symptomatic hypotension was documented. One patient had hyperkaliemia, and three other patients developed a renal impairment and a clinically relevant increase in creatinine. In seven cases, the patients suffered two side effects at the same time (Figure 1).

\subsubsection{NICMP Group}

Nine NICMP patients (15\%) discontinued ARNI treatment, in two cases, for an unknown cause. Four patients had symptomatic hypotension. One patient had hyperkaliemia, and two patients developed WRF (Figure 1).

\subsection{Incidence of Ventricular Tachyarrhythmia and Mortality in ICMP and NICMP Patients after ARNI}

At one-year follow-up, ventricular tachyarrhythmias including ventricular fibrillation (VF), non-sustained ventricular tachycardia (nsVT), and ventricular tachycardia (VT) were lower in the NICMP group compared with the ICMP group $(17.24 \%$ vs. $38.71 \% ; p=0.07)$ (Table 2). However, the long-term mortality rate was similar in both groups (Figure 2).

\subsection{The Impact of Device Therapy on Outcome and Predictors for Mortality}

At baseline, CRT-D and ICD were implanted in $24.59 \%$ and $68.85 \%$ of ICMP patients and in $32.2 \%$ and $46.67 \%$ of NICMP patients, respectively. The impact of device therapy on outcome was also evaluated. In this sub-analysis, the mortality rate in ICD patients was lower compared with that in patients with a CRT-D $(6.1 \%$ vs. $10 \% ; p<0.001)$. Concerning ventricular tachyarrhythmias, the rate of documented events in ICD patients was significantly higher than in CRT-D patients $(45.1 \%$ vs. $32 \% ; p=0.003)$ (Table 3$)$. In the multivariate analysis, the aldosterone antagonist was determined as a relevant predictor for the reduction in mortality (HR 0.21; 95\%CI 0.05-0.82; $p=0.03$, Table 4).

Table 2. Tachyarrhythmia occurrence in ICMP and NICMP patients at baseline, 6-, and 12-month follow-ups.

\begin{tabular}{|c|c|c|c|c|}
\hline Variables & $\begin{array}{l}\text { Baseline and after ARNI } \\
\qquad n=121\end{array}$ & $\begin{array}{l}\text { NICMP } \\
n=60\end{array}$ & $\begin{array}{l}\text { ICMP } \\
n=61\end{array}$ & $p$-Value * \\
\hline \multicolumn{5}{|c|}{$\begin{array}{c}\text { Arrhythmia } n(\%) \\
\text { Ventricular tachyarrhythmia }\end{array}$} \\
\hline Baseline $\Omega$ & 14/113 (12.39) & $6 / 56(10.71)$ & 8/57 (14.04) & 0.78 \\
\hline 6 months & $11 / 86(12.79)$ & $3 / 41(7.32)$ & $8 / 45(17.78)$ & 0.20 \\
\hline 12 months & $17 / 60(28.33)$ & $5 / 29(17.24)$ & $12 / 31(38.71)$ & 0.07 \\
\hline \multicolumn{5}{|c|}{ Ventricular fibrillation } \\
\hline Baseline & $3 / 113(2.65)$ & $2 / 56(3.57)$ & $1 / 57(1.75)$ & 0.62 \\
\hline 6 months & $3 / 86(3.49)$ & $0 / 41(0.00)$ & $3 / 45(6.67)$ & 0.24 \\
\hline 12 months & $5 / 60(8.33)$ & $1 / 29(3.45)$ & 4/31 (12.90) & 0.36 \\
\hline \multicolumn{5}{|l|}{ nsVT } \\
\hline Baseline & 9/87 (10.34) & $4 / 38(10.53)$ & $5 / 49(10.20)$ & 1.00 \\
\hline 6 months & $7 / 78(8.97)$ & $1 / 36(2.78)$ & $6 / 42(14.29)$ & 0.12 \\
\hline 12 months & $15 / 54(27.78)$ & $5 / 25(20.00)$ & $10 / 29(34.48)$ & 0.24 \\
\hline \multicolumn{5}{|c|}{ Ventricular tachycardia } \\
\hline Baseline & $5 / 113(4.42)$ & $3 / 56(5.36)$ & $2 / 57(3.51)$ & 0.68 \\
\hline 6 months & $4 / 86(4.65)$ & $2 / 41(4.88)$ & $2 / 45(4.44)$ & 1.00 \\
\hline 12 months & 8/60 (13.33) & $3 / 29(10.34)$ & 5/31 (16.13) & 0.71 \\
\hline
\end{tabular}

${ }^{*} p$-values for the comparison between NICMP and ICMP patients after ARNI; $\Omega$, events during 6-12 months before ARNI; SD, standard deviation; nsVT, non-sustained ventricular tachycardia. 


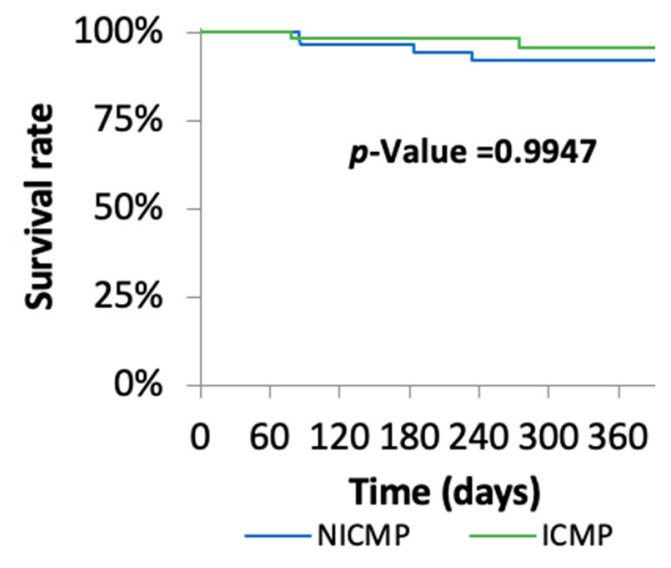

Figure 2. Kaplan-Meier survival analysis.

Table 3. Device therapy and the impact on the outcome.

\begin{tabular}{|c|c|c|c|c|c|}
\hline Device Type & CRT-D & ICD & DDD & CCM & $p$-Value \\
\hline \multicolumn{6}{|l|}{ Clinical outcomes (\%) } \\
\hline Mortality & 10 & 6.1 & 12.5 & 3.2 & $<0.001$ \\
\hline Ventricular tachyarrhythmia & 32 & 45.1 & 16.7 & 55.2 & 0.003 \\
\hline Ventricular fibrillation & 20 & 18.3 & 16.7 & 20.6 & $<0.001$ \\
\hline nsVT & 20 & 32.4 & 0 & 34.5 & $<0.001$ \\
\hline Ventricular tachycardia & 20 & 26.8 & 0 & 27.6 & $<0.001$ \\
\hline
\end{tabular}

$p$-values for the comparison between device types; CRT, cardiac resynchronization therapy; ICD, implantable cardioverter-defibrillator; DDD, dual-chamber pacemaker; CCM, cardiac contractility modulation; nsVT, non-sustained ventricular tachycardia.

Table 4. Predictors for mortality.

\begin{tabular}{|c|c|c|c|c|c|c|}
\hline \multirow{2}{*}{ Variable } & \multicolumn{3}{|c|}{ Univariate Analysis } & \multicolumn{3}{|c|}{ Multivariate Analysis } \\
\hline & HR & $95 \% \mathrm{CI}$ & $p$-Value & HR & $95 \% \mathrm{CI}$ & $p$-Value \\
\hline \multicolumn{7}{|l|}{ Patients characteristic } \\
\hline Age $>65$ & 7.43 & $0.95-58.02$ & 0.06 & & & \\
\hline Gender & 1.66 & $0.41-6.79$ & 0.48 & & & \\
\hline NICMP & 0.84 & $0.23-3.12$ & 0.79 & & & \\
\hline ICMP & 1.19 & $0.32-4.45$ & 0.79 & & & \\
\hline \multicolumn{7}{|l|}{ Medical History } \\
\hline Smoking & 0.48 & $0.15-1.56$ & 0.22 & & & \\
\hline DM type II & 5.34 & $1.42-20.13$ & 0.01 & 3.79 & $0.98-14.69$ & 0.06 \\
\hline Hypertension & 3.96 & $0.51-30.97$ & 0.19 & & & \\
\hline COPD & 1.03 & $0.22-4.79$ & 0.97 & & & \\
\hline History of Malignancy & 0.7 & $0.15-3.19$ & 0.64 & & & \\
\hline Stroke & 3.17 & $0.84-11.96$ & 0.09 & & & \\
\hline Bleeding & 2.29 & $0.29-17.89$ & 0.43 & & & \\
\hline NYHA-Classification III and IV & 31.98 & $0.02-43617.81$ & 0.35 & & & \\
\hline \multicolumn{7}{|l|}{ Electronic cardiac device } \\
\hline CRT-D & 1.26 & $0.34-4.76$ & 0.73 & & & \\
\hline ICD & 0.39 & $0.12-1.31$ & 0.13 & & & \\
\hline DDD & 1.49 & $0.19-11.63$ & 0.71 & & & \\
\hline CCM & 0.27 & $0.04-2.13$ & 0.22 & & & \\
\hline \multicolumn{7}{|l|}{ Drugs on admission } \\
\hline Beta-blocker & 21.39 & $0.00-129.5$ & 0.65 & & & \\
\hline AT-II-Antagonist & 1.56 & $0.46-5.33$ & 0.48 & & & \\
\hline Aldosterone antagonist & 0.16 & $0.04-0.59$ & 0.006 & 0.21 & $0.05-0.82$ & 0.03 \\
\hline ACE-Inhibitor & 0.88 & $0.27-2.89$ & 0.84 & & & \\
\hline Amiodarone & 0.04 & $0.00-49.87$ & 0.37 & & & \\
\hline \multicolumn{7}{|l|}{$\begin{array}{l}\text { Arrhythmia before } \\
\text { sacubitril/valsartan }\end{array}$} \\
\hline Ventricular tachyarrhythmia & 2.12 & $0.62-7.24$ & 0.23 & & & \\
\hline Ventricular fibrillation & 1.02 & $0.13-7.99$ & 0.98 & & & \\
\hline nsVT & 3.44 & $0.91-12.99$ & 0.07 & & & \\
\hline Ventricular tachycardia & 0.04 & $0.00-313.25$ & 0.49 & & & \\
\hline
\end{tabular}

Abbreviations: HR, hazard ratio; CI, confidence interval; DM, diabetes mellitus; COPD, chronic obstructive pulmonary disease; NYHA, New York Heart Association; CRT, cardiac resynchronization therapy; ICD, implantable cardioverter-defibrillator; DDD, dual-chamber pacemaker; CCM, cardiac contractility modulation; AT-II-Antagonist, angiotensin II receptor antagonist; ACE-Inhibitor, angiotensinconverting enzyme inhibitor; nsVT, non-sustained ventricular tachycardia. 


\section{Discussion}

The current study presents the incidence of ventricular tachyarrhythmias and one-year mortality in patients with ICMP in comparison with NICMP patients after ARNI. The main findings of this study are as follows: (1) The one-year mortality was similar in both groups. (2) Although ventricular tachyarrhythmias (VF, nsVT, and VT) were lower in NICMP compared with the ICMP group at one-year follow-up, LVEF increased in both groups. (3) The ICMP group suffered impairments of kidney function compared with the NICMP group. (4) Aldosterone antagonists were determined as a predictor for the reduction in mortality.

Angiotensin II receptor and neprilysin inhibition were more effective in reducing the risk for cardiovascular death or hospitalization in HF patients in comparison with ACEI alone. In addition, the PARADIGM-HF trial supported the switch from ACEI or ARB to ARNI in the treatment of symptomatic chronic heart failure [1]. Generally, the mortality rate in ICMP patients might be higher than in NICMP patients [15-17]. Furthermore, the data have shown that NICMP patients might suffer from lower events of ventricular tachyarrhythmias and do not require an ICD implantation at an advanced age [17].

In the present study, the one-year all-cause mortality rate was identical in both groups (ICMP, 6.5\% vs. NICMP, 6.6\%). Balmforth et al. reported that ARNI had a benefit in all patients regardless of the HF etiology. However, the mortality rate was higher in patients that suffered from ICMP compared with NICMP [7]. The Multicenter Defibrillator Implantation Trial (MADIT-II-trial) presented a high mortality in ICMP of $19.8 \%$ at the twenty-month follow-up. Considering the longer follow-up time than our study, this rate is higher than the rate in our study [18]. In addition, it was observed that one-year mortality rate was $29.5 \%$ after ARNI in patients, $65.2 \%$ from whom suffered from ICMP [19]. In the DEFINITE trial, NICMP patients had a higher mortality rate than our group (14.1\%). Of note, the follow-up time was twenty-nine \pm fourteen months. However, these patients did not receive the optimal medical treatment and device therapy according to the current HF guidelines [20]. Another study showed a mortality rate of $12.1 \%$ in NICMP patients who received ACEI, ARB, or ARNI [21]. We revealed a better outcome in our study compared with other published studies, but our study has a limited follow-up time of one year.

Ventricular tachyarrhythmias occur in patients suffering from HF; therefore, the impact of ARNI on these events was evaluated. In our study, ventricular arrhythmia involving VF, nsVT, and VT tended to be higher during the one-year follow-up in the ICMP group in contrast with the NICMP group, albeit without statistical significance (38.71\% vs. $17.24 \%$ ). However, the effect of ARNI compared with enalapril, irrespective of HF etiology in reducing sudden cardiac death and death from the deterioration of HF, is numerically superior [22]. Concerning this, Martens et al. provided information about the cardiac death mechanism, and they investigated the impact on the incidence of ventricular arrhythmias after switching from ACEI to ARNI. In a mean follow-up for one year, a reduction in $\mathrm{VT} / \mathrm{VF}$ and nsVT events was observed (total episodes of VT/VF pre- $n=51$ vs. post $n=14$, mean episodes of nsVT pre- $n=7.7 \pm 11.8$ vs. post $n=3.7 \pm 5.4$ ). In the study of Martens et al., $69 \%$ of observed patients had ICMP and $31 \%$ of them NICMP [23]. In addition, De Diego et al. reported that ARNI reduced ventricular arrhythmias in HErEF patients, $82 \%$ from whom suffered ICMP [24]. Our data and published data indicate a possible impact of ARNI on arrhythmias. Further data to investigate this field are needed.

Biochemical effects of the treatment with ARNI are presented in the NICMP group after therapy initiation, as reflected by circulating NT-proBNP (in ICMP, from 6266 to $6190 \mathrm{ng} / \mathrm{L}$; in NICMP, from 5132 to $1170 \mathrm{ng} / \mathrm{L}$ ). In this regard, the PIONEER-HF-trial presented that the treatment with ARNI in acutely decompensated patients was associated with a higher decrease in NT-proBNP than with the treatment with enalapril [25]. However, PIONEERHF patients were not divided according to HF etiology. Consistent with the decrease in NT-proBNP, LVEF increased in our study after medication with ARNI regardless of HF etiology at one-year follow-up (in the ICMP group, from $24.13 \% \pm 8.39$ to $32.13 \% \pm 7.53$, 
and in the NICMP group, from $25.31 \% \pm 7.68$ to $29.63 \% \pm 10.01$ ). The improvement in LVEF after ARNI was also recently observed [26].

It is known that ARNI might worsen kidney function [27]. In our study, we observed that GFR decreased consistently with an increase in creatinine after the initiation of ARNI in ICMP patients. In NICMP, GFR increased consistently with a stable level of creatinine. In this regard, one study showed that creatinine serum increased slightly after the treatment with ARNI regardless of etiology [28]. In another study, an increase in serum creatinine and a decrease in GFR were observed, with a higher tendency in valsartan patients compared with ARNI patients [29]. In the present study, the increase in LVEF in NICMP patients could be the reason that kidney function improved in patients suffering from NICMP. On the other hand, other patients did not seem to have the ability to compensate due to the hemodynamic changes after the treatment with ARNI.

In the multivariate analysis, the aldosterone antagonist was determined as a predictor for a reduction in mortality at one-year follow-up. A network meta-analysis reported that the current guideline recommendation in the treatment of HFrEF including ARNI, beta blocker, and aldosterone antagonist is superior compared with other all-medicated combinations to reduce all-cause mortality [30].

In summary, the etiology of HF plays an important role in choosing the best treatment for patients with chronic HF. ARNI seems to be effective in the treatment of HFrEF patients, with a tendency to improve cardiac function in ICMP patients and to decrease the mortality rate. However, ARNI might not impact the risk of ventricular tachyarrhythmias, particularly in ICMP patients. In addition, the improvement in renal function in NICMP patients compared with a depression of kidney function in ICMP patients is an interesting aspect. In this regard, the improvement in LVEF might lead to a lower rate of cardio-renal failure in patients suffering from NICMP.

\section{Study Limitations}

This study is a retrospective monocentric study. The number of patients suffering from ICMP and NICMP was relatively small when compared with other studies. In addition, bias due to unknown or unmeasured confounders cannot be excluded due to the retrospective nature of the study. LVEF was not systematically evaluated using, for example, cardiac magnetic resonance tomography. The NYHA class was assessed without using a qualitative evaluation questionnaire. Furthermore, some patients did not achieve the target dose in the ambulatory setting. We followed up with the patients only for twelve months. However, this study represents real-world clinical data that provide information about the effectiveness of ARNI in a heterogeneous population in clinical practice. The documentation of arrhythmias occurred by device interrogation.

\section{Conclusions}

Despite a small numerical decrease in the rates of malignant ventricular arrhythmias, the use of ARNI was not associated with differences in all-cause mortality in this small cohort of patients already treated with medical heart failure therapy and implanted devices. However, further studies are needed to investigate the impact of ARNI on the outcome according to HF etiology.

Author Contributions: Conceptualization, M.A., A.A. and I.A.; methodology, C.P. and M.K.; software, M.A., C.P. and I.E.-B.; validation, A.A.; formal analysis, I.E.-B.; investigation, I.A., A.A. and M.A.; resources, C.P., I.E.-B. and M.K.; data curation, I.E.-B., C.P. and M.K.; writing-original draft prepara-tion, M.A.; writing-review and editing, M.A., A.M., A.A. and I.A; visualization, C.P. and M.K.; supervision, M.A., J.K., M.B., A.M., A.A. and I.A; project administration, I.A.; funding acquisition, I.A. and A.A. All authors have read and agreed to the published version of the manuscript.

Funding: This research did not receive any specific grant from funding. 
Institutional Review Board Statement: The study was conducted according to the guidelines of the Declaration of Helsinki, and approved by the Institutional Review Board of University Medical Centre Mannheim, Heidelberg University (protocol code: 2018-851R-MA and date of approval: 10.07.2018).

Informed Consent Statement: Not applicable.

Data Availability Statement: The data presented in this study are available on request from the corresponding author.

Conflicts of Interest: The authors declare no competing interests.

\section{References}

1. Mcmurray, J.J.V.; Packer, M.; Desai, A.S.; Gong, J.; Lefkowitz, M.P.; Rizkala, A.R.; Rouleau, J.L.; Shi, V.C.; Solomon, S.D.; Swedberg, K.; et al. Angiotensin-Neprilysin Inhibition versus Enalapril in Heart Failure. N. Engl. J. Med. 2014, 371, 993-1004. [CrossRef] [PubMed]

2. Kenny, A.J.; Bourne, A.; Ingram, J. Hydrolysis of human and pig brain natriuretic peptides, urodilatin, C-type natriuretic peptide and some C-receptor ligands by endopeptidase-24.11. Biochem. J. 1993, 291, 83-88. [CrossRef]

3. Abumayyaleh, M.; El-Battrawy, I.; Behnes, M.; Borggrefe, M.; Akin, I. Current evidence of sacubitril/valsartan in the treatment of heart failure with reduced ejection fraction. Futur. Cardiol. 2020, 16, 227-236. [CrossRef] [PubMed]

4. Solomon, S.D.; McMurray, J.J.; Anand, I.S.; Bayes-Genis, A.; Lam, C.S.; Maggioni, A.P.; Martinez, F.; Packer, M.; Pfeffer, M.A.; Pieske, B.; et al. Angiotensin-Neprilysin Inhibition in Heart Failure with Preserved Ejection Fraction. N. Engl. J. Med. 2019, 381, 1609-1620. [CrossRef] [PubMed]

5. Packer, M.; Claggett, B.; Lefkowitz, M.P.; McMurray, J.J.V.; Rouleau, J.L.; Solomon, S.D.; Zile, M. Effect of neprilysin inhibition on renal function in patients with type 2 diabetes and chronic heart failure who are receiving target doses of inhibitors of the renin-angiotensin system: A secondary analysis of the PARADIGM-HF trial. Lancet Diabetes Endocrinol. 2018, 6, 547-554. [CrossRef]

6. Khariton, Y.; Fonarow, G.C.; Arnold, S.V.; Hellkamp, A.; Nassif, M.E.; Sharma, P.P.; Butler, J.; Thomas, L.; Duffy, C.I.; DeVore, A.D.; et al. Association Between Sacubitril/Valsartan Initiation and Health Status Outcomes in Heart Failure With Reduced Ejection Fraction. JACC Heart Fail. 2019, 7, 933-941. [CrossRef] [PubMed]

7. Balmforth, C.; Simpson, J.; Shen, L.; Jhund, P.S.; Lefkowitz, M.; Rizkala, A.R.; Rouleau, J.L.; Shi, V.; Solomon, S.D.; Swedberg, K.; et al. Outcomes and effect of treatment according to etiology in HFrEF: An analysis of PARADIGM-HF. JACC Heart Fail. 2019, 7, 457-465. [CrossRef]

8. Desai, A.S.; Solomon, S.; Claggett, B.; Mcmurray, J.; Rouleau, J.; Swedberg, K.; Zile, M.; Lefkowitz, M.; Shi, V.; Packer, M. Factors Associated With Noncompletion During the Run-In Period Before Randomization and Influence on the Estimated Benefit of LCZ696 in the PARADIGM-HF Trial. Circ. Heart Fail. 2016, 9. [CrossRef]

9. Ng, A.C.C.; Sindone, A.P.; Wong, H.S.P.; Freedman, S.B. Differences in management and outcome of ischemic and non-ischemic cardiomyopathy. Int. J. Cardiol. 2008, 129, 198-204. [CrossRef]

10. Franke, J.; Zugck, C.; Hochadel, M.; Hack, A.; Frankenstein, L.; Zhao, J.D.; Ehlermann, P.; Nelles, M.; Zeymer, U.; Winkler, R.; et al. Etiology-specific assessment of predictors of long-term survival in chronic systolic heart failure. IJC Heart Vasc. 2015, 7, 61-68. [CrossRef]

11. Corbalan, R.; Bassand, J.P.; Illingworth, L.; Ambrosio, G.; Camm, A.J.; Fitzmaurice, D.A.; Fox, K.A.; Goldhaber, S.Z.; Goto, S.; Haas, S.; et al. Analysis of outcomes in ischemic vs nonischemic cardiomyopathy in patients with atrial fibrillation: A report from the GARFIELD-AF registry. JAMA Cardiol. 2019, 4, 526-548. [CrossRef] [PubMed]

12. Ponikowski, P.; Voors, A.A.; Anker, S.D.; Bueno, H.; Cleland, J.; Coats, A.; Falk, V.; González-Juanatey, J.R.; Harjola, V.P.; Jankowska, E.A.; et al. 2016 esc guidelines for the diagnosis and treatment of acute and chronic heart failure: The task force for the diagnosis and treatment of acute and chronic heart failure of the european society of cardiology (esc). Developed with the special contribution of the heart failure association (hfa) of the esc. Eur. J. Heart Fail. 2016, 18, 891-975.

13. Damman, K.; Valente, M.A.; Voors, A.A.; O'Connor, C.M.; Van Veldhuisen, D.J.; Hillege, H.L. Renal impairment, worsening renal function, and outcome in patients with heart failure: An updated meta-analysis. Eur. Heart J. 2014, 35, 455-469. [CrossRef] [PubMed]

14. Shirakabe, A.; Hata, N.; Kobayashi, N.; Okazaki, H.; Matsushita, M.; Shibata, Y.; Nishigoori, S.; Uchiyama, S.; Asai, K.; Shimizu, W. Worsening renal function definition is insufficient for evaluating acute renal failure in acute heart failure. ESC Heart Fail. 2018, 5, 322-331. [CrossRef] [PubMed]

15. Frazier, C.G.; Alexander, K.P.; Newby, L.K.; Anderson, S.; Iverson, E.; Packer, M.; Cohn, J.; Goldstein, S.; Douglas, P.S. Associations of Gender and Etiology With Outcomes in Heart Failure With Systolic Dysfunction: A Pooled Analysis of 5 Randomized Control Trials. J. Am. Coll. Cardiol. 2007, 49, 1450-1458. [CrossRef]

16. Martínez-Sellés, M.; Doughty, R.N.; Poppe, K.; Whalley, G.A.; Earle, N.; Tribouilloy, C.; McMurray, J.J.; Swedberg, K.; Køber, L.; Berry, C.; et al. Gender and survival in patients with heart failure: Interactions with diabetes and aetiology. Results from the MAGGIC individual patient meta-analysist. Eur. J. Heart Fail. 2012, 14, 473-479. [CrossRef] [PubMed] 
17. Køber, L.; Thune, J.J.; Nielsen, J.C.; Haarbo, J.; Videbæk, L.; Korup, E.; Jensen, G.; Hildebrandt, P.; Steffensen, F.H.; Bruun, N.E.; et al. Defibrillator Implantation in Patients with Nonischemic Systolic Heart Failure. N. Engl. J. Med. 2016, 375, 1221-1230. [CrossRef]

18. Moss, A.J.; Zareba, W.; Hall, W.J.; Klein, H.; Wilber, D.J.; Cannom, D.S.; Daubert, J.P.; Higgins, S.L.; Brown, M.W.; Andrews, M.L.; et al. Prophylactic Implantation of a Defibrillator in Patients with Myocardial Infarction and Reduced Ejection Fraction. N. Engl. J. Med. 2002, 346, 877-883. [CrossRef] [PubMed]

19. Greene, S.J.; Choi, S.; Lippmann, S.J.; Mentz, R.J.; Greiner, M.A.; Hardy, N.C.; Hammill, B.G.; Luo, N.; Samsky, M.D.; Heidenreich, P.A.; et al. Clinical Effectiveness of Sacubitril/Valsartan Among Patients Hospitalized for Heart Failure With Reduced Ejection Fraction. J. Am. Heart Assoc. 2021, 10, 021459. [CrossRef]

20. Kadish, A.; Dyer, A.; Daubert, J.P.; Quigg, R.; Estes, N.M.; Anderson, K.P.; Calkins, H.; Hoch, D.; Goldberger, J.; Shalaby, A.; et al. Prophylactic Defibrillator Implantation in Patients with Nonischemic Dilated Cardiomyopathy. N. Engl. J. Med. 2004, 350, 2151-2158. [CrossRef]

21. Butt, J.H.; Nicolau, J.C.; Verma, S.; Docherty, K.F.; Petrie, M.C.; Inzucchi, S.E.; Schou, M.; Kosiborod, M.N.; Langkilde, A.M.; Martinez, F.A.; et al. Efficacy and safety of dapagliflozin according to aetiology in heart failure with reduced ejection fraction: Insights from the DAPA-HF trial. Eur. J. Heart Fail. 2021, 23, 601-613. [CrossRef]

22. Desai, A.S.; McMurray, J.J.; Packer, M.; Swedberg, K.; Rouleau, J.L.; Chen, F.; Gong, J.; Rizkala, A.R.; Brahimi, A.; Claggett, B.; et al. Effect of the angiotensin-receptor-neprilysin inhibitor LCZ696 compared with enalapril on mode of death in heart failure patients. Eur. Heart J. 2015, 36, 1990-1997. [CrossRef] [PubMed]

23. Martens, P.; Nuyens, D.; Rivero-Ayerza, M.; Van Herendael, H.; Vercammen, J.; Ceyssens, W.; Luwel, E.; Dupont, M.; Mullens, W. Sacubitril/valsartan reduces ventricular arrhythmias in parallel with left ventricular reverse remodeling in heart failure with reduced ejection fraction. Clin. Res. Cardiol. 2019, 108, 1074-1082. [CrossRef]

24. De Diego, C.; González-Torres, L.; Núñez, J.M.; Inda, R.C.; Martin-Langerwerf, D.A.; Sangio, A.D.; Chochowski, P.; Casasnovas, P.; Blazquéz, J.C.; Almendral, J. Effects of angiotensin-neprilysin inhibition compared to angiotensin inhibition on ventricular arrhythmias in reduced ejection fraction patients under continuous remote monitoring of implantable defibrillator devices. Heart Rhythm. 2018, 15, 395-402. [CrossRef]

25. Morrow, D.A.; Velazquez, E.J.; Devore, A.D.; Prescott, M.F.; Duffy, C.I.; Gurmu, Y.; McCague, K.; Rocha, R.; Braunwald, E. Cardiovascular biomarkers in patients with acute decompensated heart failure randomized to sacubitril-valsartan or enalapril in the PIONEER-HF trial. Eur. Heart J. 2019, 40, 3345-3352. [CrossRef] [PubMed]

26. Correale, M.; Mallardi, A.; Mazzeo, P.; Tricarico, L.; Diella, C.; Romano, V.; Ferraretti, A.; Leopizzi, A.; Merolla, G.; Di Biase, M.; et al. Sacubitril/valsartan improves right ventricular function in a real-life population of patients with chronic heart failure: The Daunia Heart Failure Registry. IJC Heart Vasc. 2020, 27, 100486. [CrossRef] [PubMed]

27. Solomon, S.D.; Zile, M.; Pieske, B.; Voors, A.; Shah, A.; Kraigher-Krainer, E.; Shi, V.; Bransford, T.; Takeuchi, M.; Gong, J.; et al. The angiotensin receptor neprilysin inhibitor LCZ696 in heart failure with preserved ejection fraction: A phase 2 double-blind randomised controlled trial. Lancet 2012, 380, 1387-1395. [CrossRef]

28. El-Battrawy, I.; Pilsinger, C.; Liebe, V.; Lang, S.; Kuschyk, J.; Zhou, X.; Borggrefe, M.; Röger, S.; Akin, I. Impact of Sacubitril/Valsartan on the Long-Term Incidence of Ventricular Arrhythmias in Chronic Heart Failure Patients. J. Clin. Med. 2019, 8, 1582. [CrossRef] [PubMed]

29. Voors, A.A.; Gori, M.; Liu, L.C.Y.; Claggett, B.; Zile, M.; Pieske, B.; Mcmurray, J.; Packer, M.; Shi, V.; Lefkowitz, M.P.; et al. Renal effects of the angiotensin receptor neprilysin inhibitor LCZ696 in patients with heart failure and preserved ejection fraction. Eur. J. Heart Fail. 2015, 17, 510-517. [CrossRef] [PubMed]

30. Komajda, M.; Böhm, M.; Borer, J.S.; Ford, I.; Tavazzi, L.; Pannaux, M.; Swedberg, K. Incremental benefit of drug therapies for chronic heart failure with reduced ejection fraction: A network meta-analysis. Eur. J. Heart Fail. 2018, 20, 1315-1322. [CrossRef] 